\title{
ARTIGO
}

DOI: 10.22481 /praxis.v14i28.3464

\section{UMA ANÁLISE DAS MARCAS DO PODER DISCIPLINAR NO COTIDIANO ESCOLAR DAS JUVENTUDES DO IFS ${ }^{1}$}

\author{
AN ANALYSIS OF DISCIPLINARY POWER TRADEMARKS IN THE IFS YOUTH \\ SCHOOL YOUTH
}

\section{UN ANÁLISIS DE LAS MARCAS DEL PODER DISCIPLINAR EN EL COTIDIANO ESCOLAR DE LA JUVENTUD DEL IFS}

\author{
Ana Paula Leite Nascimento \\ Universidade Federal de Sergipe - Brasil \\ Maria Helena Santana Cruz. \\ Universidade Federal de Sergipe - Brasil
}

\begin{abstract}
Resumo
O estudo analisou as marcas do poder disciplinar no cotidiano escolar das juventudes, evidenciando os investimentos na construção de corpos "dóceis" no contexto do IFS. Enfatizamos os fundamentos teóricos do poder disciplinar e seus investimentos na construção de corpos "dóceis"; e, problematizamos os regramentos escolares e o sistema disciplinar do IFS, trazendo à tona dados da análise documental do Regulamento da Organização Didática do IFS, e, da realidade socioeconômica dos/as estudantes, a fim de problematizarmos o controle e a regulação disciplinar. Caracterizou-se como uma pesquisa qualitativa e o materialismo histórico dialético enquanto método perpassou o estudo. Identificamos que a escola investe na produção de sujeitos homogêneos e de corpos "dóceis", e, em razão disso não acolhe e pune por meio do poder disciplinar aqueles/as que apresentam corporalidades e identidades que contrariam a lógica homogeneizante e a lógica imposta de docilidade-utilidade.
\end{abstract}

Palavras-chave: Corpos “dóceis”. Cotidiano escolar. Poder disciplinar.

\section{Abstract}

The study analyzed the marks of disciplinary power in the school daily life of the youths, evidencing the investments in the construction of "docile" bodies in the context of the IFS. We emphasize the

\footnotetext{
${ }^{1} \mathrm{O}$ artigo foi elaborado a partir de resultado de pesquisa qualitativa consubstanciada por levantamento bibliográfico e coleta de dados documentais no âmbito do doutorado em Educação, vinculado ao Programa de Pós-Graduação em Educação da Universidade Federal de Sergipe, como parte da fundamentação teórica e produção e análise dos dados da tese em fase de elaboração, sob a orientação da Prof ${ }^{a}$. Dr ${ }^{a}$. Maria Helena Santana Cruz.
} 
theoretical foundations of disciplinary power and its investments in the construction of "docile" bodies; and we problematize the school rules and the disciplinary system of the IFS, bringing to the fore data from the documentary analysis of the Regulation of the Educational Organization of the IFS, and the socioeconomic reality of the students, in order to problematize the control and the disciplinary regulation. It was characterized as a qualitative research and the dialectical historical materialism as method pervaded the study. We identify that the school invests in the production of homogenous subjects and of "docile" bodies, and, for this reason, does not accept and punish by means of disciplinary power those who present corporalities and identities that contradict the homogenizing logic and the imposed logic of docility -utility.

Keywords: "Docile" bodies. School daily. Disciplinary power.

\section{Resumen}

El estudio analizó las marcas del poder disciplinario en el cotidiano escolar de las juventudes, evidenciando las inversiones en la construcción de cuerpos "dóciles" en el contexto del IFS. Enfatizamos los fundamentos teóricos del poder disciplinario y sus inversiones en la construcción de cuerpos "dóciles"; y, problematizamos los reglamentos escolares y el sistema disciplinario del IFS, trayendo a la superficie datos del análisis documental del Reglamento de la Organización Didáctica del IFS, y de la realidad socioeconómica de los/las estudiantes, a fin de problematizar el control y la regulación disciplinaria. Se caracterizó como una investigación cualitativa y el materialismo histórico dialéctico como método pasaba el estudio. Identificamos que la escuela invierte en la producción de sujetos homogéneos y de cuerpos "dóciles", y, en razón de ello no acoge y castiga por medio del poder disciplinar aquellos que presentan corporalidades e identidades que contrarían la lógica homogeneizante y la lógica impuesta de docilidad-utilidad.

Palabras clave: Cuerpos "dóciles". Cotidiano escolar. Poder disciplinario.

\section{Introdução}

Nesse estudo nos propomos ao objetivo de realizar uma análise das marcas do poder disciplinar que estão presentes no cotidiano escolar das juventudes, buscando evidenciar os investimentos na construção de corpos "dóceis" particularizados no contexto do Instituto Federal de Educação, Ciência e Tecnologia de Sergipe (IFS). Em razão disso, traremos à tona reflexões relacionadas ao processo de regulação de gênero e ao processo de regulações sociais a partir da disciplina ou poder disciplinar na perspectiva de indagarmos e problematizarmos as regulações existentes no âmbito da vida social e seus rebatimentos no contexto da vida escolar, cotidiano marcado por normatizações, ritos e regramentos escolares, e, também por medidas e punições disciplinares, como materialização das regulações que as juventudes são submetidas.

Desta feita, enfatizaremos a respeito do poder disciplinar e seus investimentos na construção de corpos "dóceis"; e, problematizaremos os regramentos escolares e o sistema disciplinar do IFS. Apresentaremos dados da análise documental do Regulamento da 
Organização Didática do IFS relativos às disposições que tratam da finalidade, dos direitos e dos deveres dos/as estudantes, das proibições aos/às estudantes e do sistema disciplinar direcionado aos/às estudantes, com o fito de problematizar o controle e a regulação disciplinar no ambiente escolar. Também faremos a exposição de dados do ano letivo de 2015, cursado em 2016, que expressam a realidade socioeconômica dos/as estudantes inseridos/as nos programas, serviços e ações de Assistência Estudantil que o IFS dispõe no intuito de questionar a medida disciplinar de cancelamento de bolsa de Assistência Estudantil. Por fim, registraremos algumas notas conclusivas captadas no percurso teórico e análises desenvolvidas nesse estudo.

Em se tratando dos aspectos metodológicos, o trabalho caracterizou-se como uma pesquisa qualitativa, norteada pela combinação de elementos explicativos e descritivos. Realizamos levantamento bibliográfico para fundamentar a discussão teórica e consubstanciar as análises. Fizemos coleta de dados documentais para assinalar as marcas do poder disciplinar no cotidiano escolar e subsidiar a problematização e análise que nos propusemos neste estudo. A organização, análise e interpretação dos dados foram realizadas a partir de categorias definidas durante o estudo à luz do referencial teórico, construído no percurso da investigação. Nessa pesquisa nos referenciamos no materialismo histórico dialético enquanto método que perpassou o estudo e transversalizou o levantamento bibliográfico e a coleta de dados, bem como a organização, a análise e a interpretação dos dados.

\section{O poder disciplinar e seus investimentos na construção de corpos "dóceis"}

O cotidiano da vida escolar vivenciado pelas juventudes presentes no IFS é marcado por regulações, normas, regramentos e medidas e penalidades disciplinares que ancorados pelo poder disciplinar vão se constituindo como os fundamentos na construção de corpos "dóceis" (FOUCAULT, 1993), tendo, por sua vez, como materialização desse processo os investimentos educacionais e disciplinares que vão dando as bases para a "escolarização dos corpos e mentes" (LOURO, 1997) das juventudes. As normas estão diretamente ligadas à produção de parâmetros de pessoas (BUTLER, 2014); logo, podemos afirmar que as normas e os regramentos escolares do IFS intencionam produzir parâmetros de juventudes. Considerando o poder disciplinar latente na cotidianidade da escola, as juventudes produzidas serão certamente aqueles/as estudantes regidos a partir de uma relação imposta de docilidadeutilidade, como pondera Foucault (1993), implicando na construção de corpos “dóceis”. 
O poder disciplinar no âmbito da escola se materializa, portanto, através da disciplina escolar que historicamente atravessa a cultura escolar. Convém apontarmos que como legado da disciplina escolar tem-se a produção de uma série de conhecimentos, valores e comportamentos cuja finalidade é educar os/as estudantes de acordo com padrões sociais, culturais e morais (CHAVES, 2006; MARQUES, 2011), que alicerçam a cultura escolar de construção de corpos "dóceis" (FOUCAULT, 1993) e de "escolarização dos corpos e mentes" (LOURO, 1997).

Marques (2011) chama a atenção para a necessidade de situarmos o cotidiano escolar tendo a compreensão de que diversos sujeitos participam da cultura escolar. É conveniente acrescentarmos que as categorias classe, gênero, etnia, geração, dentre outras, perpassam a construção desses sujeitos ao longo de suas trajetórias de vidas, por conseguinte, essas categorias também perpassam a cultura escolar que esses sujeitos vão construindo na dinâmica das escolas em que estão inseridos.

Com isso capturamos então que a disciplina escolar modela os corpos desde a infância, o que implica em expectativas de que as juventudes por terem vivenciado trajetórias escolares anteriores já cheguem às etapas escolares que sucedem às etapas escolares da infância com os corpos modelados, disciplinados, dóceis, escolarizados; do contrário, os/as jovens estudantes terão que ser submetidos/as a processos de regulações que produzam esses resultados mediados pelo exercício do poder disciplinar.

Foucault (1993, p.163) assinala que "houve, durante a época clássica, uma descoberta do corpo como objeto e alvo de poder". Pondera ainda que "encontraríamos facilmente sinais dessa grande atenção dedicada então ao corpo - ao corpo que se manipula, se modela, se treina, que obedece, responde, se torna hábil ou cujas forças se multiplicam" (FOUCAULT, 1993, p.163). Demarca, pois, que "é dócil um corpo que pode ser submetido, que pode ser utilizado, que pode ser transformado e aperfeiçoado" (IBID., p. 163).

Os métodos que "permitem o controle minucioso das operações do corpo, que realizam a sujeição constante de suas forças e lhes impõem uma relação de docilidadeutilidade, são o que podemos chamar as "disciplinas"” (FOUCAULT, 1993, p.164). Cabe ressaltarmos neste estudo que "muitos processos disciplinares existiam há muito tempo: nos conventos, nos exércitos, nas oficinas também. Mas as disciplinas se tornaram no decorrer dos séculos XVII e XVIII fórmulas gerais de dominação" (FOUCAULT, 1993, p. 164).

Tem-se que o momento histórico das disciplinas se constituiu nos marcos do momento em que 
[...] nasce uma arte do corpo humano, que visa não unicamente o aumento de suas habilidades, nem tampouco aprofundar sua sujeição, mas a formação de uma relação que no mesmo mecanismo o torna tanto mais obediente quanto é mais útil, e inversamente. Forma-se então uma política das coerções que são um trabalho sobre o corpo, uma manipulação calculada de seus elementos, de seus gestos, de seus comportamentos. O corpo humano entra numa maquinaria de poder que o esquadrinha, o desarticula e o recompõe. Uma "anatomia política", que é também igualmente uma "mecânica do poder", está nascendo; ela define como se pode ter domínio sobre o corpo dos outros, não simplesmente para que façam o que se quer, mas para que operem como se quer, com as técnicas, segundo a rapidez e a eficácia que se determina. (FOUCAULT, 1993, p.164).

Logo, a disciplina "fabrica [...] corpos submissos e exercitados, corpos 'dóceis'. A disciplina aumenta as forças do corpo (em termos econômicos de utilidade) e diminui essas mesmas forças (em termos políticos de obediência)" (IBID., p.164-165). Frente a esses pressupostos chega-se à conclusão que "ela dissocia o poder do corpo; faz dele por um lado uma 'aptidão', uma 'capacidade' que ela procura aumentar" (IBID., p.165); e então "inverte por outro lado a energia, a potência que poderia resultar disso, e faz dela uma relação de sujeição estrita" (IBID., p.165). É imprescindível salientarmos que "se a exploração econômica separa a força e o produto do trabalho, digamos que a coerção disciplinar estabelece no corpo o elo coercitivo entre uma aptidão aumentada e uma dominação acentuada" (IBID., p.165).

Foucault (1993, p.165) nos alerta que

[...] a "invenção" dessa nova anatomia política não deve ser entendida como uma descoberta súbita. Mas como uma multiplicidade de processos muitas vezes mínimos, de origens diferentes, de localizações esparsas, que se recordam, se repetem, ou se imitam, apóiam-se uns sobre os outros, distinguem-se segundo seu campo de aplicação, entram em convergência e esboçam aos poucos a fachada de um método geral.

Nessa direção a nova anatomia política da disciplina, isto é, do poder disciplinar pode ser encontrada "[...] em funcionamento nos colégios, muito cedo; mais tarde nas escolas primárias; investiram lentamente o espaço hospitalar; e em algumas dezenas de anos reestruturam a organização militar" (FOUCAULT, 1993, p.165). Demarca-se que "circularam às vezes muito rápido de um ponto a outro (entre o exército e as escolas técnicas ou os colégios e liceus), às vezes lentamente e de maneira mais discreta (militarização insidiosa das grandes oficinas)" (IBID., p.165). 
Desta feita, "a mística do cotidiano [...] se associa à disciplina do minúsculo" (FOUCAULT, 1993, p.166). Vale enfatizarmos que "a minúcia dos regulamentos, o olhar esmiuçante das inspeções, o controle das mínimas parcelas da vida e do corpo [...]” (IBID., p.167) vão dando “[...] no quadro da escola, do quartel, do hospital ou da oficina, um conteúdo laicizado, uma racionalidade econômica ou técnica a esse cálculo místico do ínfimo e do infinito" (IBID., p.167). Consequentemente a disciplina do detalhe vai ganhando força em muitas dimensões e espaços da vida cotidiana, logo, também da vida escolar.

A disciplina "procede em primeiro lugar à distribuição dos indivíduos no espaço. Para isso, utiliza diversas técnicas" (FOUCAULT, 1993, p.168). As técnicas recorridas são "sempre minuciosas, muitas vezes íntimas, mas que têm sua importância: porque definem um certo modo de investimento político e detalhado do corpo, uma nova 'microfísica' do poder" (IBID., p.165); e, igualmente "porque não cessaram, desde o século XVII, de ganhar campos cada vez mais vastos, como se tendessem a cobrir o corpo social inteiro" (IBID., p.165). Destaca-se que o espaço escolar funciona "[...] como uma máquina de ensinar, mas também de vigiar, de hierarquizar, de recompensar" (IBID., p.173), no qual as disciplinas ao tempo em que organizam "as 'celas', os 'lugares' e as 'filleiras' criam espaços complexos: ao mesmo tempo arquiteturais, funcionais e hierárquicos" (IBID., p.174). Desse modo, a arte das distribuições dos espaços utilizada pela disciplina culmina na constituição de espaços que

[...] realizam a fixação e permitem a circulação; recortam segmentos individuais e estabelecem ligações operatórias; marcam lugares e indicam valores; garantem a obediência dos indivíduos, mas também uma melhor economia do tempo e dos gestos. São espaços mistos: reais pois que regem a disposição de edifícios, de salas, de móveis, mas ideais, pois projetam-se sobre essa organização caracterizações, estimativas, hierarquias. A primeira das grandes operações da disciplina é então a constituição de "quadros vivos" que transformam as multidões confusas, inúteis ou perigosas em multiplicidades organizadas. (FOUCAULT, 1993, p.174).

Neste estudo daremos atenção aos efeitos da disciplina, ou seja, do exercício do poder disciplinar na cotidianidade da vida escolar, buscando demarcar e problematizar alguns dos efeitos que impactam as juventudes presentes no cotidiano escolar do IFS. O poder disciplinar "é com efeito um poder que, em vez de se apropriar e de retirar, tem como função maior 'adestrar'; ou sem dúvida adestrar para retirar e se apropriar ainda mais e melhor" (FOUCAULT, 1993, p.195). Isto posto, tem-se que a disciplina 
[...] "fabrica" indivíduos; ela é a técnica específica de um poder que toma os indivíduos ao mesmo tempo como objetos e como instrumentos de seu exercício. Não é um poder triunfante que, a partir de seu próprio excesso, pode-se fiar em seu superpoderio; é um poder modesto, desconfiado, que funciona a modo de uma economia calculada, mas permanente. Humildes modalidades, procedimentos menores, se os compararmos aos rituais majestosos da soberania ou aos grandes aparelhos do Estado. E são eles justamente que vão pouco a pouco invadir essas formas maiores, modificarlhes os mecanismos e impor-lhes seus processos. (FOUCAULT, 1993, p.195).

Portanto, "o sucesso do poder disciplinar se deve sem dúvida ao uso de instrumentos simples: o olhar hierárquico, a sanção normalizadora e sua combinação num procedimento que lhe é específico, o exame" (IBID., p.195). Assim, a atuação do poder disciplinar se dá por meio da vigilância hierárquica que consiste em poder enxergar a tudo e a todos, estabelecendo uma rede onde todos são observados; da sanção normalizadora através da existência de uma modalidade punitiva, na qual os mínimos atos desviantes do indivíduo sejam passíveis de penalização, via correção ou punição; e, também do exame, caracterizado por permitir uma alta visibilidade do indivíduo, processo que intensifica sua individualização mediante sua descrição pormenorizada, destacando suas diferenças frente aos demais sujeitos. (FOUCAULT, 1993).

Partimos da premissa que a escola não comporta apenas a sua estrutura física visível que expressa o seu modelo arquitetônico, mas a escola é também um espaço que dispõe de estruturas invisíveis que, tendo por excelência a disciplina como alicerce de seu funcionamento, expressam o "modelo" de corpo dócil, ou seja, de indivíduo dócil que se busca construir e que muitas das vezes é construído no interior dos muros deste ambiente escolarizado, notadamente sob o jugo do exercício do poder disciplinar. Logo, a escola é um dos espaços em que as identidades e subjetividades dos sujeitos são construídas. Por isso concordamos com a assertiva de que

[...] a escola, como a maioria das instituições sociais, é um constructo de cimento e sonhos, é uma mistura de materiais de construção, como cal, tijolo, água, e mãos hábeis e/ou cérebros ágeis, como é o caso de um pedreiro, de um servente ou de um professor, que são expertos na arte e na técnica de construção, especialistas em fazer paredes e construir portas, em levantar e/ou derrubar monumentos, em escrever cartografias e mapear os desejos mais íntimos, mestres de obras e, principalmente, de pessoas, construtores e construtoras de identidades, "acimentadores" e "acimentadoras" de subjetividades. (ANDRADE, 2013, p.47). 
Dada a prerrogativa de que na escola as identidades e as subjetividades são construídas, por conseguinte, as marcas da escola vão modelando os sujeitos que ali se constroem e constroem outros sujeitos. Processo que resulta em: corpos e mentes escolarizados como alude Louro (1997), especialmente em razão de a escola delimitar aquilo que pode ser feito e igualmente aquilo que não pode ser feito. É necessário que problematizemos o fato de que

[...] a escola delimita espaços. Servindo-se de símbolos e códigos, ela afirma o que cada um pode (ou não pode) fazer, ela separa e institui. Informa o "lugar" dos pequenos e dos grandes, dos meninos e das meninas. Através de seus quadros, crucifixos, santas ou esculturas, aponta aqueles/as que deverão ser modelos e permite, também, que os sujeitos se reconheçam (ou não) nesses modelos. O prédio escolar informa a todos/as sua razão de existir. Suas marcas, seus símbolos e arranjos arquitetônicos "fazem sentido", instituem múltiplos sentidos, constituem distintos sujeitos. (LOURO, 1997, p.58).

Esse cenário nos mostra, entretanto, que é preciso atentarmos para a questão de que "a geografia que vemos em cada prédio, a organização dos alicerces, a gramática dos espaços e a ortografia das repartições não obedecem, com exclusividade, ao rigor dos pedreiros ou dos professores do presente" (ANDRADE, 2013, p.47-48). Com isso presume-se que a lógica possa ser inversa: "são os professores, os gestores, os pedreiros, os serventes, os secretários de educação, os prefeitos, os governadores, os arquitetos e os mestres de obras que obedecem à lógica do controle e da disciplina” (IBID., p.48), que se impõe desde marcos temporais que antecedem os séculos XX e XXI.

\section{Problematizando os regramentos escolares e o sistema disciplinar do IFS}

É imperioso demarcar que tanto a organização escolar como a gestão escolar não podem ser concebidas como se estivessem isoladas da dinâmica da sociedade, vez que estão inseridas em um todo social, econômico, político e cultural, isto é, numa totalidade que se estabelece a partir de um constante processo de transformação que acompanha a produção e reprodução da vida social. Cabe registrar que quando ocorrem mudanças na produção e reprodução da vida social, consequentemente as suas mudanças são acompanhadas por toda uma reorganização social, jurídica, política e cultural, que, por conseguinte, mais cedo ou mais tarde rebaterá no complexo da educação. É o modo de produção da vida material, isto é, a produção da objetividade (que produz a subjetividade), que torna possível a forma da 
organização da vida social, inclusive a organização da escola e até mesmo a sua gestão e administração escolar (LOMBARDI; ANDREOTTI, 2010). Avaliamos ser pertinente apontarmos que

[...] ao longo da história, [considerando a formação e desenvolvimento das diferentes classes sociais] as diferentes comunidades (e no interior delas, os diferentes grupos sociais) construíram modos também diversos de conceber e lidar com o tempo e o espaço: valorizaram de diferentes formas o tempo do trabalho e o tempo do ócio; o espaço da casa ou o da rua; delimitaram os lugares permitidos e os proibidos (e determinaram os sujeitos que podiam ou não transitar por eles); decidiram qual o tempo que importava (o da vida ou o depois dela); apontaram as formas adequadas para cada pessoa ocupar (ou gastar) o tempo... Através de muitas instituições e práticas, essas concepções foram e são aprendidas e interiorizadas; tornam-se quase "naturais" (ainda que sejam "fatos culturais"). A escola é parte importante desse processo. (LOURO, 1997, p.59-60).

Isto posto, é indispensável afirmar que para capturarmos as formas de constituição dos sujeitos no âmbito da vida social não podemos desconsiderar que as vivências no cotidiano escolar ocupam significativa relevância no processo de constituição dos sujeitos, por sua vez, na constituição de suas identidades e subjetividades. Desse modo, concordamos com Louro (1997, p.59) quando alude que

[...] os sentidos precisam estar afiados para que sejamos capazes de ver, ouvir, sentir as múltiplas formas de constituição dos sujeitos implicadas na concepção, na organização e no fazer cotidiano escolar. O olhar precisa esquadrinhar as paredes, percorrer os corredores e salas, deter-se nas pessoas, nos seus gestos, suas roupas; é preciso perceber os sons, as falas, as sinetas e os silêncios; é necessário sentir os cheiros especiais; as cadências e os ritmos marcando os movimentos de adultos e crianças. Atentas/os aos pequenos indícios, veremos que até mesmo o tempo e o espaço da escola não são distribuídos nem usados - portanto, não são concebidos - do mesmo modo por todas as pessoas.

Registramos que o nosso intento com esse estudo não se situa no bojo do desejo de macular a imagem da instituição escolar em análise, mas em darmos evidência ao processo de exercício do poder disciplinar no interior da escola. Para isso iremos problematizar as regulações e os investimentos na construção de corpos "dóceis" por meio da exposição e análise de alguns dos artigos do Regulamento da Organização Didática (ROD), vigente, do IFS, aprovado pela Resolução no 35/2016/CS/IFS, que normatiza e disciplina o cotidiano dos/as estudantes presentes neste ambiente educacional. Neste estudo damos destaque às 
juventudes matriculadas em cursos técnicos do ensino médio integrado e do subsequente nos campi do IFS. Vejamos:

No Título I do ROD, Da Finalidade, no Artigo $1^{\circ}$, identificamos que o ROD tem por finalidade "normatizar as atividades acadêmicas que permeiam os cursos de formação inicial e continuada, técnicos, de graduação e de pós-graduação lato sensu” (IFS, 2016a, grifo original). Esse documento se impõe como instrumento de normatização e regulação das atividades acadêmicas que supõe também a normatização e a regulação do cotidiano escolar, e, igualmente dos sujeitos que se constroem nesse espaço e o constrói, bem como das suas práticas (manifestações de suas culturas, identidades, individualidades e subjetividades) e dos modos como vivenciam os diversos espaços escolares, que são atravessados por inúmeras relações de poder.

Consideramos esse documento como uma das expressões dos movimentos curriculares presentes na escola, que cumprem a função de construir, ensinar e regular as corporalidades (CAETANO, 2013), que no caso da escola objetiva construir corpos "dóceis" através da disciplina, isto é, do poder disciplinar. É forçoso apontarmos que em virtude das "inúmeras instâncias sócio-educativas por onde passam os sujeitos que integram as escolas e, por sua vez, os interesses implicados nos seus fazeres pedagógicos, não [podemos limitar] a formação dos movimentos curriculares à escola" (CAETANO, 2013, p.66), mas é fato que no ambiente da escola eles se fazem presentes de forma significativa no que se refere à organização da escola e de suas pedagogias, às práticas disciplinares (medidas e penalidades), e, especialmente nas regulações das corporalidades das juventudes, implicando na forma como constroem e manifestam as diversidades de suas culturas, identidades, individualidades e subjetividades.

No Título IV, Da comunidade acadêmica, Capítulo II, Dos estudantes, faremos indagações e problematizações a respeito de alguns dos deveres do/a estudante que constam na Seção II, Dos Deveres, no Artigo 127, bem como acerca de algumas das proibições demarcadas na Seção III, Das Proibições, no Artigo 128, quando então iremos expor e problematizar alguns dos deveres e proibições conjuntamente no caso das similitudes que venham apresentar.

Quanto ao dever de "I-contribuir para manter o prestígio e o bom conceito do IFS" (IFS, 2016a), asseveramos que nos casos em que o bom conceito do IFS estiver relacionado ao bom desempenho em atividades acadêmicas, científicas, culturais, esportivas, dentre outras atividades ligadas ao tripé ensino, pesquisa e extensão, cabe questionarmos como o/a 
estudante poderá cumprir esse dever sem a garantia das condições de acesso, permanência e êxito por meio das ações de Assistência Estudantil regulamentadas pelo Decreto $\mathrm{n}^{\circ}$ 7.234/2010 que dispõe sobre o Programa Nacional de Assistência Estudantil (PNAES), dada a conjuntura nacional e local $^{2}$ de precarização e desfinanciamento das ações de Assistência Estudantil, uma realidade igualmente vivenciada no contexto do IFS.

Se manter o prestígio e o bom conceito do IFS estiver relacionado a princípios e valores morais, a exemplo da lealdade para evitar mácula à imagem institucional, como supõe o dever de "XIX-ser leal à Instituição, não cometendo atos ou fazendo declarações que possam macular sua imagem" (IFS, 2016a), cabem questionamentos: Qual tipo de lealdade exige-se dos/as jovens estudantes matriculados/as no IFS? Uma lealdade que corresponda por acaso ao silenciamento e à invisibilidade das culturas, identidades, individualidades e subjetividades das juventudes ali presentes? Pontuamos que a questão da lealdade e de não cometer atos ou declarações que maculem a imagem escolar deve ser problematizada, pois aparece como um princípio que responsabiliza os/as estudantes pela preservação da escola como uma instituição sem máculas. Principalmente devemos problematizar isso porque o que se atribui muitas das vezes como mácula à imagem institucional relaciona-se a questões de cunho moralizante que julgam chocar e desonrar a escola, porém, são práticas e subjetividades que constituem as identidades e corporalidades das juventudes que se constroem e se manifestam de modo a contrariar e a subverter os "modelos" que a lógica disciplinar da escola almeja e (re)produz hegemonicamente: tanto os tipos de sujeitos como os tipos de suas práticas que ideologicamente apresentam relação com os regimes patriarcalista, capitalista e heterossexista, que direcionam a produção e reprodução da vida social.

Aí está implícita a finalidade da escola em produzir corpos "dóceis" (FOUCAULT, 1993) e "corpos e mentes escolarizadas" (LOURO, 1997) que não coloquem em risco a imagem da escola, que por hipótese alguma maculem a sua imagem, sendo que contraditoriamente a escola comete atos e faz declarações que maculam as suas juventudes de distintas formas, notadamente quando classificam e hierarquizam os/as tipos de estudantes e de suas práticas, tendo como mecanismos as suas pedagogias escolares, principalmente a pedagogia da sexualidade que classifica e hierarquiza as sexualidades que se diferenciam do padrão da heteronormatividade como "anormais", "desviantes", “erradas", "pecaminosas". (LOURO, 2000; 2009).

\footnotetext{
${ }^{2}$ Detalhamento e análise da realidade local vivenciada no contexto do IFS acerca das ações de Assistência Estudantil poderão ser encontrados In: NASCIMENTO, Ana Paula Leite; SANTOS, Josiane Soares. Assistência Estudantil no IFS. Aracaju: Edifs, 2014.
} 
Problematizamos o dever de "XXV-adotar postura ética, moral e legal no desempenho discente" (IFS, 2016a), pois mais uma vez constatamos que em função da produção de corpos “dóceis" há o reforço da adoção de posturas morais no desempenho discente. Destacamos que a postura moral preponderante no interior da escola referencia-se em padrões morais que só reforçam as classificações e hierarquizações que se fazem aos/às estudantes e às suas práticas no contexto escolar, o que acontece de forma pejorativa, constrangedora, agressiva, opressora e LGBTfóbica nos casos em que a escola se depara com cenas que afirmam causar pânico moral no cotidiano escolar quando há subversão da lógica heterossexista que é (re)produzida na escola.

O dever de "V-trajar uniforme se estudante de curso técnico de nível médio, nas formas integrada, subsequente e concomitante" no Artigo 127 (IFS, 2016a), e, a proibição de "IV- circular e permanecer nas dependências da instituição usando trajes incompatíveis com o ambiente de ensino-aprendizagem" no Artigo 128 (IFS, 2016a), em que se propaga a ideia de que o traje compatível com o ambiente escolar seja o uniforme, nos levam a demarcarmos que não obstante o uniforme tenha a função de identificar os/as estudantes como pertencentes institucionalmente à escola, convém apontarmos que o uniforme também exerce a função de controle e mais ainda: aparece como um mecanismo que reforça a dimensão de homogeneidade que a escola intenciona produzir e reproduzir na dinâmica da cotidianidade escolar, invisibilizando assim as múltiplas e distintas identidades e corporalidades sob as quais as juventudes se constroem e expressam os muitos e diversos modos de viver, ser e estar no mundo.

Aqui vale expor que "a forma extrema de roupa convencional é o traje totalmente determinado pelo outro: o uniforme" (LURIE, 1997, p.33). Logo, "independente do tipo militar, civil, [escolar] ou religioso; [...] vestir [...] fardas é abdicar o direito de agir individualmente - em termos de discurso falado é estar, parcial ou totalmente, sob censura" (IBID., p.33). Nesse sentido, “o que se faz, assim como o que se veste, será determinado por autoridades externas - em um maior ou menor grau, dependendo de quem se é [...]” (IBID., p.33). Assim, "tirar um uniforme é geralmente um alívio [...]; às vezes também é um sinal de rebeldia" (IBID., p.33) ou mesmo, no caso do uniforme escolar, de manifestar as heterogeneidades e diversidades que constituem as identidades e corporalidades das juventudes quando estas deixam de ir ao ambiente escolar sem o uniforme ou ainda quando fazem algum tipo de modificação ao personalizarem ou customizarem o uniforme escolar para que se transforme com essa ressignificação em política própria de visibilidade como parte de 
suas identidades e corporalidades. A esse respeito Louro (2000, p.12) pondera que as transgressões, ou seja, adaptações e modificações por mais simples que sejam no uniforme traduzem a nossa “[...] tentava [de] introduzir alguma marca pessoal que [possa] afirmar 'esta[e] sou eu'".

Em se tratando do dever de "XI-aguardar o professor em sala de aula, evitando permanecer nas áreas de circulação" (IFS, 2016a), denota para a necessidade de problematizarmos os motivos que justificam evitar a circulação nos ambientes escolares enquanto os/as estudantes aguardam seus/as professores/as chegarem. Desde que não atrapalhem o andamento e desenvolvimento de outras aulas e atividades não vemos problemas no fato de os/as estudantes permanecerem nas áreas de circulação da escola até que o/a professor/a chegue na sala. O controle nesse caso é tão nítido que inviabiliza que os/as estudantes constituam uma relação com a escola e seus ambientes, e, relações de sociabilidade entre os/as estudantes.

No dever de "XXIV - não praticar carícias íntimas, de cunho libidinoso, no interior do IFS" no Artigo 127 (IFS, 2016a), e, na proibição de "II- [...] praticar atos [...] libidinosos [...]" no Artigo 128 (IFS, 2016a), evidenciamos que o controle dos corpos se dá numa dimensão normatizada e principalmente a partir da normalização, vez que muitas das práticas disciplinares do controle dos corpos ocorrem quando se presencia simplesmente aproximações afetivas dos corpos e muito mais quando se trata de corpos de estudantes do mesmo sexo, quando se instala aí uma espécie de pânico moral. Situações em que os/as estudantes são até enquadrados no rol de práticas indisciplinares, posto que não primaram pelo dever de não praticar carícias íntimas, de cunho libidinoso no ambiente escolar, sendo penalizados/as como se as aproximações afetivas dos corpos fossem literalmente o próprio ato libidinoso, devasso, impudico. Identificamos neste tipo de ação disciplinar a pedagogia da prevenção muito mais das sexualidades que subvertem o padrão da heteronormatividade do que de um possível ato sexual que pudesse vir a acontecer dentro dos muros escolares. A necessidade de reiteração e normalização da heteronormatividade (LOURO, 2009) nos mostra que a pedagogia da prevenção de práticas sexuais que não se encaixam em práticas heterossexistas pode até ser justificada nos espaços escolares para preservar a imagem escolar nos limites dos muros escolares e também para além dos muros escolares, evitando atos e declarações que maculem a imagem da escola, por conseguinte, que os/as estudantes sejam leais à Instituição como dever normatizado no inciso XIX. 
Esse contexto nos mostra que a vigilância hierárquica como um dos instrumentos que se recorre para o exercício do poder disciplinar, como alude Foucault (1993), ocupa centralidade no cotidiano escolar. Ele demarca que por meio da vigilância hierárquica podiase dar concretude aos seguintes objetivos:

[...] adestrar corpos vigorosos, imperativo de saúde; obter oficiais competentes, imperativo de qualificação; formar militares [e outros indivíduos] obedientes, imperativo político; prevenir a devassidão e a homossexualidade, imperativo de moralidade. (FOUCAULT, 1993, p.197198).

Apesar de estes objetivos da vigilância hierárquica terem sido assinalados por Foucault a partir de situações que se deram em marcos temporais anteriores ao que ora vivenciamos, é nítida a preponderância ainda nos tempos atuais desses imperativos (de saúde, de qualificação, político e de moralidade) que ele expôs nos estudos que realizou, mais especificamente com relação aos recursos para o bom adestramento dos corpos, ou seja, para a construção de corpos "dóceis". No cenário em estudo observamos que os imperativos de qualificação, político e de moralidade são os que mais predominam.

Tem-se que "na essência de todos os sistemas disciplinares, funciona um pequeno mecanismo penal". [...] As disciplinas estabelecem uma 'infra-penalidade'; [...] e reprimem um conjunto de comportamentos [...]." (FOUCAULT, 1993, p.202). Nesse sentido, é imprescindível trazermos à tona que na escola

[...] funciona como repressora toda uma micropenalidade do tempo (atrasos, ausências, interrupções das tarefas), da atividade (desatenção, negligência, falta de zelo), da maneira de ser (grosseria, desobediência), dos discursos (tagarelice, insolência), do corpo (atitudes "incorretas", gestos não conformes, sujeira), da sexualidade (imodéstia, indecência). Ao mesmo tempo é utilizada, a título de punição, toda uma série de processos sutis, que vão do castigo [...] leve a privações ligeiras e a pequenas humilhações. Trata-se ao mesmo tempo de tornar penalizáveis as frações mais tênues da conduta, e de dar uma função punitiva aos elementos aparentemente indiferentes do aparelho disciplinar: levando ao extremo, que tudo possa servir para punir a mínima coisa; que cada indivíduo se encontre preso numa universalidade punível-punidora. (FOUCAULT, 1993, p.203).

A disciplina "traz consigo uma maneira específica de punir, e que é apenas um modelo reduzido do tribunal. $\mathrm{O}$ que pertence à penalidade disciplinar é a inobservância, tudo o que está inadequado à regra, tudo o que se afasta dela, os desvios" (IBID., p.202). Vale dar ênfase que "o castigo disciplinar tem a função de reduzir os desvios. Deve portanto ser 
essencialmente corretivo" (IBID., p. 204, grifo original). A "penalidade perpétua que atravessa todos os pontos e controla todos os instantes das instituições disciplinares compara, diferencia, hierarquiza, homogeniza, exclui. Em uma palavra, ela normaliza” (IBID., p. 207). É por meio das disciplinas que aparece "o poder da Norma". [...] O Normal se estabelece como princípio de coerção no ensino [...]" (IBID., p. 208). Assim como a vigilância e junto com ela, a regulamentação se impõe como um dos grandes instrumentos de poder ao final da era clássica. Portanto, as

[...] marcas que significavam status, privilégios, filiações, tendem a ser substituídas ou pelo menos acrescidas de um conjunto de graus de normalidade, que são sinais de filiação a um corpo social homogêneo, mas que têm em si mesmos um papel de classificação, de hierarquização e de distribuição de lugares. Em certo sentido, o poder de regulamentação obriga à homogeneidade; mas individualiza, permitindo medir os desvios, determinar os níveis, fixar as especialidades e tornar úteis as diferenças, ajustando-as umas às outras. (FOUCAULT, 1993, p.208-209).

Dados esses pressupostos, faremos a seguir a exposição e análise de alguns dos artigos relacionados ao Sistema Disciplinar adotado no IFS. No Capítulo III, Do Sistema Disciplinar, Seção I, Das Finalidades, no Artigo 133, verificamos que

[...] o sistema disciplinar, aplicável aos professores e estudantes terá a finalidade de contribuir com a formação do educando, o bom funcionamento dos trabalhos escolares, o entrosamento dos vários serviços, o cumprimento efetivo das normativas internas e a obtenção dos objetivos neles previstos. (IFS, 2016a).

Problematizaremos aqui somente o sistema disciplinar aplicável aos/as estudantes, dada à particularidade do estudo. Na Seção III, Das Medidas Disciplinares aplicadas aos Estudantes, no Artigo 135, identificamos que "os estudantes matriculados em regime de residência estão sujeitos à perda do benefício de Moradia Estudantil quando do descumprimento de qualquer dos artigos dispostos neste Regulamento.” (IFS, 2016a). Essa constatação nos inquieta ao tempo em que nos fornece subsídios para afirmarmos que as medidas disciplinares são tão severas e arbitrárias que por descumprimento de qualquer dos artigos dispostos no ROD os/as estudantes em regime de residência ficam sujeitos à perda do benefício de Moradia Estudantil. É inevitável fazermos questionamentos: Por quais motivos naturaliza-se o fato de uma penalidade disciplinar comprometer as condições de permanência dos/as estudantes ao deliberar e homologar a perda do benefício de Moradia Estudantil, 
concedido, na perspectiva de direito, ao/a estudante que atendeu ao perfil de vulnerabilidade socioeconômica para se inserir no Programa de Assistência e Acompanhamento ao Educando (PRAAE) do IFS, na linha de ações de vulnerabilidade socioeconômica? Porventura neste ambiente escolar não se prioriza assegurar as condições de permanência?

No Artigo 136 constam algumas medidas disciplinares, quais sejam:

[...] aos estudantes serão aplicadas as seguintes medidas disciplinares, de acordo com a gravidade da infração, do envolvimento, dolo e/ou culpa: Iadvertência verbal; II- advertência escrita; III- suspensão individual ou coletiva; IV- ressarcimento; V- transferência ex-officio, em caso de reincidência da suspensão, independente do motivo. (IFS, 2016a).

A medida disciplinar de suspensão individual ou coletiva, no inciso III, nos leva a algumas indagações: Por que no ambiente que prima pelo ensino/aprendizagem e almeja o bom desempenho escolar investe-se em medidas disciplinares que colocam em xeque essas premissas? Por acaso em nome da produção de corpos "dóceis" compromete-se o processo de ensino/aprendizagem (quando se suspende individual ou coletivamente a participação dos/as estudantes nas atividades escolares)?

Classificamos como arbitrária e severa a medida disciplinar de transferência ex-officio, em caso de reincidência da suspensão, independente do motivo, de acordo com o disposto no inciso $\mathrm{V}$, posto que independente do motivo da reincidência da suspensão delibera-se pela transferência ex-officio, justificada por dever do cargo ou por obrigação da função, sem atentar-se para as relações de aprendizados e relações sociais que são estabelecidas no cotidiano da vida escolar como ambiente em que as suas trajetórias escolares e de vida são construídas, já que abruptamente, mesmo que se garanta ampla defesa e o contraditório, essas relações são interrompidas com a transferência ex-officio.

No Artigo 139 constatamos marcas do poder disciplinar no IFS. Vejamos:

[...] o estudante que sofrer medida disciplinar será destituído automaticamente do cargo de representante da turma, se for o caso, bem como, a depender da gravidade de sua falta, por decisão unânime da Comissão Disciplinar, ter cancelamento de possível bolsa proveniente de assistência estudantil ou de pesquisa acadêmica que esteja recebendo, por um prazo de um ano a partir da aplicação da penalidade. (IFS, 2016a).

Sobre o disposto neste artigo é forçoso apresentarmos algumas considerações e problematizações relacionadas prioritariamente à Assistência Estudantil. O conjunto das ações 
que foram sendo demandadas pelos/as estudantes da classe trabalhadora, que vivenciam cotidianamente dificuldades de acesso e permanência nos ambientes educacionais em que se inserem, intitula-se como "Assistência Estudantil, enquanto política de enfrentamento ao velho e crônico enigma da evasão, da repetência e, especialmente, das desigualdades econômicas, sociais e culturais, como traços presentes na educação brasileira" (NASCIMENTO, 2014, p. 73, grifos originais). Na conjuntura atual as ações de Assistência Estudantil estão regulamentadas pelo Decreto $n^{\circ} 7.234 / 2010$ que dispõe sobre o Programa Nacional de Assistência Estudantil (PNAES). Conforme Artigo $3^{\circ}$, Parágrafo $1^{\circ}$, deste Decreto, as ações de assistência estudantil do PNAES deverão ser desenvolvidas nas seguintes áreas:

I - moradia estudantil; II - alimentação; III - transporte; IV - atenção à saúde; V - inclusão digital; VI - cultura; VII - esporte; VIII - creche; IX - apoio pedagógico; e X - acesso, participação e aprendizagem de estudantes com deficiência, transtornos globais do desenvolvimento e altas habilidades e superdotação. (BRASIL, 2010).

Cabe registrar que de acordo com o Artigo $5^{\circ}$, do Decreto em comento, "serão atendidos no âmbito do PNAES prioritariamente estudantes oriundos da rede pública de educação básica ou com renda familiar per capita de até um salário mínimo e meio [...]." (BRASIL, 2010, grifo original). Desta feita, as ações do PNAES "se caracterizam como ações afirmativas de permanência, destinadas, prioritariamente, a alunos[as] oriundos[as] das camadas populares, objetivando promover efetivas condições para a realização e conclusão do curso [...]" (MAGALHÃES, 2012, p.96).

Haja vista que o que desejamos problematizar no Artigo 139 do ROD relaciona-se à questão do cancelamento de bolsa proveniente de assistência estudantil do/a estudante que cometeu algum ato indisciplinar, que, por sua vez, tem sido uma "justificativa" para a instituição chegar a esse ponto de cancelar bolsa e/ou auxílio que é determinante para a garantia das condições de permanência do/a estudante penalizado/a, não podemos, portanto, desprezar a realidade socioeconômica dos/as estudantes que se inserem nos programas, serviços e ações de Assistência Estudantil que o IFS dispõe. Por isso iremos expor dados do perfil socioeconômico destes/as estudantes de acordo com o detalhamento a seguir. Para tanto, nos referenciaremos em dados ${ }^{3}$ do ano letivo 2015, cursado em 2016, coletados no IFS e que foram acessados até esse momento do estudo.

\footnotetext{
${ }^{3}$ Estamos aguardando mais dados relacionados ao ano letivo 2015 (cursado em 2016) e ao ano letivo 2016 (que foi cursado em 2017), posto que até a presente data ainda não foram disponibilizados.
} 
De acordo com os dados acessados sobre renda per capita familiar (IFS, 2016b), constatamos que a renda per capita familiar mais preponderante entre os/as estudantes foi a menor que meio salário mínimo, perfazendo 36,84\%, correspondente ao total de 931 (novecentos e trinta e um) estudantes. Em seguida com 22,39\% foi a renda per capita familiar entre um salário mínimo e um salário mínimo e meio, cujo total de estudantes foi 566 (quinhentos e sessenta e seis). Aparece depois a renda per capita familiar entre meio salário mínimo e um salário mínimo com o percentual de 21,32\%, tendo 539 (quinhentos e trinta e nove) estudantes. A renda per capita familiar de um salário mínimo e meio a dois salários mínimos e meio contabilizou 11,87\%, com 300 (trezentos) estudantes. Notamos que as rendas per capitas com menores percentuais entre os/as estudantes foram as rendas que contabilizam maior montante financeiro, sendo as seguintes: de dois salários mínimos e meio a três salários mínimos com apenas 3,16\%, representando 80 (oitenta) estudantes; e a renda maior que três salários mínimos com somente 4,39\%, equivalendo ao total de 111 (cento e onze) estudantes.

É necessário também assinalarmos dados do perfil acerca da origem escolar dos/as estudantes matriculados/as no IFS, conforme veremos a seguir. Com base nos dados que acessamos, observamos que os/as estudantes matriculados/as no IFS no ano letivo 2015 foram aqueles/as majoritariamente oriundos/as de escolas públicas com 78,56\%. Esse total de estudantes com origem escolar da rede pública pode ser distribuído em escola pública estadual com $60,75 \%$, concentrando o maior percentual; escola pública municipal com 14,82\%; e, escola pública federal com apenas 2,99\%.

Considerando o perfil de vulnerabilidade socioeconômica das juventudes presentes no IFS, como mostram os dados relativos à per capita familiar dos/as estudantes matriculados/as no IFS em 2015, cujo perfil majoritariamente se concentra nas per capitas familiares menores que meio salário mínimo até um salário mínimo e meio, com o total de 80,55\%, evidenciando um quadro alarmante e agravante da condição de vulnerabilidade socioeconômica desses/as estudantes; considerando que a origem escolar desses/as jovens concentra-se nas escolas da rede pública com 78,56\%, em conformidade com o perfil prioritário de atendimento no âmbito do PNAES (estudantes oriundos da rede pública de educação básica ou com renda familiar per capita de até um salário mínimo e meio), é imprescindível questionarmos a penalidade disciplinar de "[...] cancelamento de possível bolsa proveniente de assistência estudantil ou de pesquisa acadêmica que [o/a estudante] esteja recebendo, por um prazo de um ano a partir da aplicação da penalidade” prevista no Artigo 139. 
Esses dados justificam questionarmos também o direito de "I- igualdade de condições para acesso e permanência na Instituição" e o direito de "VIII-ter asseguradas as condições necessárias ao desenvolvimento pleno de suas potencialidades, na escala social e individual", assinalados no Artigo 126 do ROD (no Título IV, Da comunidade acadêmica, Capítulo II, Dos estudantes, Seção I, Dos Direitos). Julgamos ser indispensável questionar as condições de acesso e permanência, considerando inclusive as demandas e necessidades estudantis daqueles/as estudantes que tem sido alvo de LGBTfobia no cotidiano escolar a partir das expressões e materialização da violência e opressão que sofrem, especialmente quando manifestam corporalidades, identidades e subjetividades que contrariam, subvertem e resistem à lógica da heteronormatividade que é (re)produzida na escola, que, em nossa avaliação, se faz presente no cotidiano da escola como um mecanismo que associa-se aos investimentos na construção de corpos "dóceis", já que as classificações, hierarquizações, punições e "necessidades" de correções (disciplinares ou não) frente aos supostos desvios que perpassam o ideário dos padrões heteronormativos semelhantemente perpassam a lógica da docilidade-utilidade. Dadas essas premissas, interrogamos o que vem sendo feito para assegurar os direitos relacionados às condições de acesso e permanência (inciso I), bem como os direitos atinentes às condições necessárias ao desenvolvimento pleno das potencialidades (inciso VIII) às diversidades de juventudes que ali se constroem e constrói o ambiente escolar?

Um cotidiano escolar sem a garantia das condições de permanência nos casos em que se delibera pelo cancelamento de bolsas vinculadas às ações de Assistência Estudantil e sem as condições de realização de pesquisa quando se homologa pelo cancelamento de bolsa de pesquisa acadêmica, ambos os cancelamentos como um ato de medida disciplinar, cuja penalidade é aplicada através de portaria pelo Reitor ou Diretor Geral do Campus, como visto no parágrafo $4^{\circ}$ do Artigo 136, implica em interrogarmos se nesta realidade educacional a centralidade é para a penalidade disciplinar ao invés de ser para a garantia das condições de acesso e permanência (abarcando aqui também a garantia das condições de pesquisa)?

No caso do cancelamento de bolsas e/ou auxílios vinculados às ações de Assistência Estudantil ou mesmo do cancelamento de bolsas de pesquisa acadêmica vinculadas diretamente às ações de Pesquisa, Extensão ou Inovação Tecnológica (e, indiretamente vinculadas às ações de Assistência Estudantil que partindo de uma concepção ampla abarca ações ligadas ao tripé institucional de ensino, pesquisa e extensão) como uma penalidade disciplinar, precisamos evidenciar que contraria os direitos de "igualdade de condições para 
acesso e permanência na Instituição" e de "ter asseguradas as condições necessárias ao desenvolvimento pleno de suas potencialidades, na escala social e individual”, previstos no Artigo 126, incisos I e VIII, respectivamente, do Regulamento da Organização Didática, enquanto documento oficial local, e, igualmente direitos previstos em outras legislações de abrangência nacional que suplantam a legislação de caráter institucional.

Ante o exposto, avaliamos que a impossibilidade da continuidade da garantia do acesso às condições de permanência e também a impossibilidade da continuidade do desenvolvimento de atividades de pesquisa acadêmica em razão da necessidade de reforçar as medidas disciplinares e suas sanções e penalidades contribuem na caracterização desse espaço educacional como um espaço em que o que se impera não é tão somente a vigilância hierárquica, mas, sobretudo, as sanções normalizadoras, transformando-se em um espaço de juízo, como uma espécie de tribunal e julgamento acompanhado de suas aplicações de penalidades como elucida Foucault (1993). Logo, esse retrato escolar se impõe como um contrassenso na medida em que contraria os objetivos do PNAES, dispostos no seu Artigo $2^{\circ}$, a saber:

I - democratizar as condições de permanência dos jovens na educação [...]; II - minimizar os efeitos das desigualdades sociais e regionais na permanência e conclusão da educação [...]; III - reduzir as taxas de retenção e evasão; e IV - contribuir para a promoção da inclusão social pela educação. (BRASIL, 2010).

É imperioso questionarmos uma medida disciplinar como essa que desconsidera as demandas e necessidades estudantis de acesso e permanência, inviabilizando o atendimento de demandas e necessidades por meio de programas, projetos e serviços preconizados pelo PNAES, e, desconsidera a relevância da pesquisa para o processo de ensino/aprendizagem e desempenho acadêmico-escolar dessas juventudes.

Acrescentamos ainda que o cancelamento da bolsa de Assistência Estudantil e de pesquisa acadêmica associa-se ao castigo disciplinar que tem a finalidade de reduzir os desvios, pois castigar funcionaria como educar na perspectiva de corrigir os desvios apresentados, "justificando", por sua vez, a penalidade disciplinar aplicada, haja vista que "o efeito corretivo que [...] se espera [da punição disciplinar] apenas de uma maneira acessória passa pela expiação e pelo arrependimento; é diretamente obtido pela mecânica de um castigo”. (FOUCAULT, 1993, p.204). Na esteira dessa discussão avaliamos que a penalidade disciplinar do cancelamento das bolsas se impõe como um dos investimentos na construção 
de corpos "dóceis" numa tentativa de reduzir aquilo que consideram e classificam como desvios dos/as estudantes, atendendo à lógica disciplinar presente na escola que exalta o/a estudante disciplinado/a e corrige e pune o/a indisciplinado/a como marcas do poder disciplinar no cotidiano das juventudes.

\section{Notas conclusivas}

Nesse estudo problematizamos as relações de poder que se estabelecem no cotidiano do IFS a partir da análise de um dos seus documentos (o Regulamento da Organização Didática), priorizando trazer à tona os movimentos curriculares e as pedagogias escolares que transversalizam a cotidianidade deste ambiente educacional, notadamente os efeitos que impactam e regulam as juventudes que ali estudam, se constroem e constrói mutuamente aquele espaço, processo que é atravessado por identidades "escolarizadas" e investimentos cotidianos que vão na direção da construção de corpos "dóceis", ou seja, por marcas que materializam o poder disciplinar na escola.

Vimos que o exercício da disciplina supõe um "dispositivo que obrigue pelo jogo do olhar; um aparelho onde as técnicas que permitem ver induzam a efeitos de poder, e onde, em troca, os meios de coerção tornem claramente visíveis aqueles sobre quem se aplicam" (FOUCAULT, 1993, p.196). Paradoxalmente o mesmo ambiente escolar em que os/as estudantes ficam visíveis para que então possam lhes ser aplicadas as medidas disciplinares e/ou sanções normalizadoras, a invisibilidade também se instala, contudo, o que se busca tornar invisíveis são as culturas, identidades, individualidades e subjetividades juvenis, especialmente aquelas que apontam para a subversão dos padrões ditos normais, ou seja, que vão na contramão das expectativas dos corpos "dóceis" e também das feminilidades e masculinidades hegemônicas.

A escola investe na produção de sujeitos homogêneos e de corpos "dóceis", e, em razão disso não acolhe e por vezes acaba punindo através do poder disciplinar aqueles/as que se apresentam como sujeitos com corporalidades e identidades que contrariam essa lógica homogeneizante e também a lógica imposta de docilidade-utilidade quando expressam suas diversidades culturais, de identidades de gênero e identidades sexuais, como manifestações de suas individualidades e subjetividades.

Embora pelo próprio caráter normatizador e disciplinador da lógica escolar as práticas de subversões (a forma como recusam ou questionam alguns dos aprendizados da escola, bem 
como as medidas e penalidades escolares que objetivam a construção dos corpos "dóceis" por meio da escolarização dos corpos e mentes) das juventudes sejam alvos de medidas disciplinares que podem chegar às penalidades até de suspensões da escola ou cancelamento de auxílios e/ou bolsas da Assistência Estudantil e de pesquisa acadêmica como constatamos no caso do IFS, desconsiderando veementemente a condição de vulnerabilidade socioeconômica que esses/as estudantes se encontram, além de desconsiderar a necessidade de realização de pesquisa; precisamos, pois, enfatizar neste estudo a caracterização das práticas de subversões das juventudes como mecanismos de questionamentos às normas e regulações (tanto as regulações de gênero como as outras regulações disciplinares presentes no interior da escola) hegemônicas de organização da vida social que se refletem na dinâmica de organização da vida escolar, sendo concebidas, portanto, como práticas de resistências e contra hegemônicas das juventudes enquanto exercício de poder e como enfrentamento aos ditames do poder disciplinar que marcam suas vivências e trajetórias.

\section{Referências}

ANDRADE, Luma Nogueira de. Hierarquia, disciplina e panoptismo: uma cartografia do espaço escolar. In: RODRIGUES, Alexsandro; BARRETO, Maria Aparecida Santos Corrêa (Org.). Currículos, gêneros e sexualidades: experiências misturadas e compartilhadas. Vitória, ES: Edufes, 2013, p.47-61.

BRASIL. Decreto no 7.234, Dispõe sobre o Programa Nacional de Assistência Estudantil PNAES. de 19 de Julho de 2010. Diário Oficial [da] República Federativa do Brasil, Ministério da Educação, Brasília, 2010.

BUTLER, Judith. Regulações de gênero. Cadernos Pagu, n.42, jan-jun., 2014, p. 250-274. Disponível em: http://dx.doi.org/10.1590/0104-8333201400420249. Acesso em: 27 dez. 2016.

CAETANO, Márcio. Movimentos curriculares e a construção da heteronormatividade. In: RODRIGUES, Alexsandro; BARRETO, Maria Aparecida Santos Corrêa. (Org.). Currículos, gêneros e sexualidades: experiências misturadas e compartilhadas. Vitória, ES: Edufes, 2013, p.63-82.

CHAVES, Miriam. Um estudo sobre a cultura escolar no Rio de Janeiro dos anos 1930 pelas lições de história. Revista Brasileira de História da Educação, v. 11, 2006, p. 71-100.

FOUCAULT, Michel. Vigiar e punir: nascimento da prisão. 10. ed. Petrópolis: Vozes, 1993. 
IFS. Instituto Federal de Sergipe. Regulamento da Organização Didática do Instituto Federal de Educação, Ciência e Tecnologia de Sergipe, [aprovado através da] Resolução no 35/2016/CS/IFS, Aracaju, 2016a.

IFS. Instituto Federal de Sergipe. Relatório de Gestão: exercício de 2015. Aracaju: 2016b.

LOMBARDI, José Claudinei; ANDREOTTI, Azilde L. A importância da abordagem histórica da gestão educacional. In: LOMBARDI, José Claudinei; MINTO, Lalo Watanabe. (Org.). História da administração escolar no Brasil: do diretor ao gestor. Campinas-SP: Alinea, 2010.

LOURO, Guacira Lopes. Gênero, sexualidade e educação: uma perspectiva pósestruturalista. 6. ed. Petrópolis, RJ: Editora Vozes Ltda., 1997.

LOURO, Guacira Lopes. Pedagogias da sexualidade. In: LOURO, Guacira Lopes. (Org). O corpo educado: pedagogias da sexualidade. 2 ed. Belo Horizonte: Autêntica, 2000, p.4-24.

LOURO, Guacira Lopes. Heteronormatividade e Homofobia. In: JUNQUEIRA, Rogério Diniz (Org.). Diversidade sexual na educação: problematizações sobre a homofobia nas escolas. Brasília: Ministério da Educação, Secretaria de Educação Continuada, Alfabetização e Diversidade, UNESCO, 2009, p.85-93.

LURIE, Alison. A linguagem das roupas. Rio de Janeiro: Rocco, 1997.

MAGALHÃES, Rosélia Pinheiro de. Desigualdade, pobreza e educação superior no Brasil. In: FONAPRACE - Revista Comemorativa 25 anos: histórias, memórias e múltiplos olhares, Minas Gerais: UFU - MG, 2012, p.88-97.

MARQUES, Gabriel Rodrigues Daumas. A educação do corpo e o protagonismo discente no Colégio Pedro II: mediações entre o ideário republicano e a memória histórica da instituição (1889-1937). Dissertação (Mestrado em Educação) - Universidade Federal do Rio de Janeiro, Centro de Filosofia e Ciências Humanas, Rio de Janeiro, 2011. 174p.

NASCIMENTO, Ana Paula Leite. Uma análise das ações de assistência estudantil no contexto do Instituto Federal de Educação, Ciência e Tecnologia de Sergipe. 2014. Dissertação (Mestrado em Serviço Social) - Universidade Federal de Sergipe, São Cristóvão. 153p.

\section{$\underline{\text { SOBRE AS AUTORAS }}$}

\section{Ana Paula Leite Nascimento}

Doutoranda em Educação pela Universidade Federal de Sergipe (UFS). Assistente Social do Instituto Federal de Educação, Ciência e Tecnologia de Sergipe (IFS), lotada no Campus Lagarto, localizado na cidade de Lagarto - SE, vinculada à Gerência de Apoio e Inclusão (GAI). Membro do Grupo de Pesquisa: "Educação, Formação, Processo de Trabalho e Relações de Gênero” (UFS). E-mail: paulajcbrasil@ yahoo.com.br 


\section{Maria Helena Santana Cruz}

Professora Emérita da Universidade Federal de Sergipe (UFS); Pós-Doutora em Sociologia da Educação pela UFS; Doutora e Mestra em Educação pela Universidade Federal da Bahia (UFBA). Atualmente é professora dos Programas de Pós-Graduação em Educação (PPGED) e Serviço Social (PROSS) da UFS. Coordenadora da Rede Feminista Norte-Nordeste de Estudos e Pesquisas Interdisciplinares sobre a Mulher e Relações de Gênero (REDOR), período 2016/2018. Coordenadora do Núcleo de Estudos Interdisciplinares de Pesquisa sobre a Mulher e Relações de Gênero (NEPIMG) da UFS, integrado à REDOR. Foi Secretária Regional da Sociedade Brasileira para o Progresso da Ciência (SBPC) em Sergipe (1990/1992). Integra o Comitê ad hoc do Programa Pró Equidade de Gênero da Subsecretaria de Articulação Institucional da Secretaria Especial de Políticas para as Mulheres (SPM) da Presidência da República (PR). Coordena o Grupo do diretório de Pesquisa do CNPq: Educação, Formação, Processo de Trabalho e Relações de Gênero. E-mail: helenacruz@uol.com.br 